\title{
Simulation of Empty Container Logistic Management at Depot
}

\author{
San-Nah Sze ${ }^{1, a)}$, Siaw-Ying Doreen Sek ${ }^{1, b)}$, Kang-Leng Chiew ${ }^{1, c)}$ \\ and Wei-King Tiong ${ }^{1, \mathrm{~d})}$ \\ ${ }^{I}$ Department of Computational Science and Mathematics, \\ Faculty of Computer Science and Information Technology, Universiti Malaysia Sarawak, \\ 94300 Kota Samarahan, Sarawak, Malaysia \\ a) Corresponding author: psnsze@unimas.my \\ b) doreenying92@gmail.com, ${ }^{\text {c) }}$ klchiew@unimas.my, ${ }^{\mathrm{d})}$ wktiong@unimas.my
}

\begin{abstract}
This study focuses on the empty container management problem in a deficit regional area. Deficit area is the area having more export activities than the import activities, which always have a shortage of empty container. This environment has challenged the trading companies in the decision making in distributing the empty containers. A simulation model that fit to the environment is developed. Besides, a simple heuristic algorithm with some hard and soft constraints consideration are proposed to plan the logistic of empty container supply. Then, the feasible route with the minimum cost will be determined by applying the proposed heuristic algorithm. The heuristic algorithm can be divided into three main phases which are data sorting, data assigning and time window updating.
\end{abstract}

\section{INTRODUCTION}

The empty container management is one of the ongoing issues in the maritime trade or shipping companies. Based on Crainic and Delorm, about 40 to 50 percent of containers transportation are allocate to empty container movement [1]. According to Iannone et al., the empty container reposition problem not only affected the maritime transportation system but also affected the inland transportation system [2]. The inland containerisation problem will be more complex and functional compared to maritime containerisation problem. The uncertainty of the customer's demand and various types of the ship's capacity and container's size have increased the difficulty in finding the solution and the decision making process [3]. However, limited research has been conducted on the study of coordination mechanisms of the empty container management in the inland regional area [4].

Besides, empty container management is non-revenue, time consuming and also a relative expensive project. Hence, most companies intended to cut down the cost on it. On the other hand, the container transportation route is always the critical problem for a shipping company. The delay of any section will probably affects other parts because most of them are linked with one another. Thus, an efficient truck schedules that can satisfying all container transportation demands for a fixed time horizon is desirable.

This project focuses on a deficit area with the limited empty container meanwhile it is the region that having more export activities than import activities. The background of the project is similar as the diagram below.

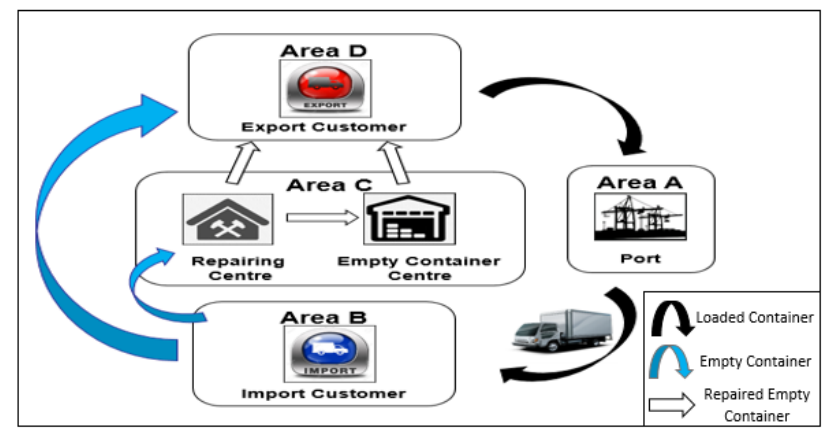

FIGURE 1. Layout for the empty container deficit area 